\title{
The Prospective Consumers of the Indonesian Green Aviation Initiative for Sustainable Development in Air Transportation
}

\author{
Ismi Rajiani ${ }^{1,2, *(D)}$ and Sebastian Kot ${ }^{3,4, * \text { (D) }}$ \\ 1 Department of Business Administration \& Port Management, STIA Dan Manajemen Kepelabuhan \\ Barunawati, Perak Barat 173, Surabaya 60165, Indonesia \\ 2 Research Synergy Foundation, Jalan Kancra No. 11, Bandung 40262, Indonesia \\ 3 The Management Faculty, Czestochowa University of Technology, Armii Krajowej 19B, \\ 42-201 Częstochowa, Poland \\ 4 Faculty of Economic Sciences and IT, North-West University, Vaal Triangle Campus, P.O. Box 1174, \\ Vanderbijlpark 1900, South Africa \\ * Correspondence: ismi.rajiani@stiamak.ac.id (I.R.); sebacat@zim.pcz.czest.pl (S.K.); \\ Tel.: +48-34-3250-330 (S.K.)
}

Received: 6 April 2018; Accepted: 27 May 2018; Published: 29 May 2018

\begin{abstract}
The Indonesia government's pledge on moderation climate change and greenhouse gas decline will affect the development of energy and transportation. However, shifting to these new green products is naturally problematic. Recognizing the prospective customer is even more challenging if there is no prediction base. This study is concentrated on discerning the inclinations to forecast the potential consumers by applying Schwartz's Portrait Value Questionnaire (PVQ), mediated with three established groups, namely: the (1) LOHAS (Lifestyle of Health and Sustainability); (2) traditionalists and (3) career-oriented. By referring to five diffusions of an innovation model, the adopters who are prospectively using the green aviation are assessed. The negative path to technology enthusiast and visionaries denote no market. However, if these two niches are found, they will become the focal point for segmenting the market. The relationship among the constructs is assessed using structural equation modeling on 178 samples that are residing in main cities of Indonesia.
\end{abstract}

Keywords: green aviation product; market segmentation; technology enthusiast; sustainability

\section{Introduction}

At the 2009 G20 summit, the Indonesian president promised a voluntary target of a $26 \%$ decrease in greenhouse gas (GHG) emissions, below the business-as-usual level, by 2020, based on unilateral actions, and a further reduction of up to $41 \%$ below business-as-usual, if sufficient international back up would be available to the government. This corresponds to Indonesia's commitment with The United Nations Framework Convention on Climate Change (UNFCCC), which is to be achieved through seven mitigation actions, namely: (1) sustainable peat land management; (2) reducing the rate of deforestation and land degradation; (3) developing carbon sequestration projects in forestry and agriculture; (4) promoting energy efficiency; (5) developing alternative and renewable energy sources; (6) reducing solid and liquid waste; and (7) shifting to low-emission transportation modes. A presidential decree on the national action plan to reduce greenhouse emissions was signed in 2011. The plan further establishes the GHG emissions reduction from five priority sectors (forestry and peat lands, agriculture, energy and transportation, industry, and waste) to contribute to meeting the target of $26 \%$ in 2019. This policy is a cross-sectoral plan addressing areas such as agriculture, forestry, industry, 
energy, and infrastructure, with instruments such as taxation, investment policies, and awareness raising. The advancement, however, has been sluggish, even though enormous financial support has been provided.

As part of a presidential commitment to actively participate in and contribute to global climate change mitigation, Indonesia's Directorate General of Civil Aviation (DGCA) and the Ministry of Transportation have entered into an agreement with the International Civil Aviation Organization (ICAO), to help the country tackle emissions from its civil aviation sector. The state-owned airline, Garuda Indonesia, has confirmed that it is targeting a 3\% use of biofuels in its jet fuel consumption from 2020, by combination of fleet renewal, airport initiatives, air navigation improvements, and the use of alternative fuels. However, in analyzing the impacts of the Carbon Neutral Growth from 2020 (CNG2020) strategy on airline environmental inefficiency, based on the predicted data of 29 international airlines during 2021-2023, Garuda Indonesia is predicted to be the largest inefficiency during 2021-2023 [1].

One of the International Civil Aviation Organization's (ICAO's) instructions for reducing climate pollution is to develop a global market-based measure (MBM) so as to retain net carbon emissions from an international flight at the same level, starting in 2020. However, a key issue in recent international climate summits, the Green Climate Fund (GCF) has been confronted with the problem of insufficient financing. The GCF financing heavily depends on contributions from developed countries, even if the donor parties are extended to emerging economics. To make this worse, the United States has withdrawn from climate finance, which will significantly increase the burden for other donors [2].

A new high-tech product or service is typically introduced in the niche market rather than the mass-market [3,4]. As sustainability has moved in the middle-of-the-road political outline [5], regardless of the current unfavorable financial condition of the Green Climate Fund, Indonesian airlines must be ready to implement the green aviation initiative. Thus, the ability to identify groups with a high perspective to become new customers is therefore tremendously precious, in order to safeguard the efficiency of the presidential decree. The reviewed 53 empirical articles on green purchase behavior from 2000 to 2014 indicated that consumer's environmental concern and products functional attributes had emerged as the two major determinants for consumer green purchase behavior [6]. However, in the case of Indonesia, where the sustainability marketing issue is still in the early infant stage, which segment of consumers, who are of a significant environmental concern to become the target market, is likely the most critical issue. This study strives to make two specific contributions to the environmental literature. Firstly, although studies on green segmentation have been conducted in various contexts in Western countries $[7,8]$ none have explored the consumer profiling in the air transport sector of a non-Western economy, particularly in developing countries. This research intends to fill that knowledge gap by exploring whether an environmentally-oriented market niche exists in the air transport industry in a developing country like Indonesia. Secondly, this study profiles the airline industry's consumers based on their environmental behaviors, by examining the values that are vital in order to predict their attitudes and behavior towards the environment, as values are claimed to be more operative for profiling and segmenting potential users [9-11]. The findings of this study, therefore, may provide airline marketers with a better understanding of the consumers' profile and likewise may offer guidelines for green marketing activities, to reach these environmentally aware customers.

\section{A New High Tech Product Market Profiling}

To contribute to the ICAO global program, Indonesia has promised to improve fleet fuel efficiency by $1.5 \%$ per year, until 2020 . New technology aircraft and new fuel for aviation are included in the action plan to reduce emissions in the aviation sector.

Although Indonesia is a broad-minded nation regarding industrial development, her people are conventional in most business transactions and are usually ruled by real familiarity. This way, a new initiative, such as familiarizing renewable energy and green flight, which are viewed by the Indonesian 
population as a new way of flying using newly developed high tech aircraft and new energy, as well as friendly environment operation, may not deliver relief for decision-makers to obligate themselves to, until it is verified satisfactory. This notion is confirmed by the findings that most companies in Indonesia run through green initiatives without the severe course of action on greenways. At the same time, some companies that have been green in practices do not endorse themselves as being a green company for the motive that they do not want to be regarded as partaking in 'greenwashing'. Greenwashing is an action of dishonesty that is accomplished by placing the company or product as being naturally responsive, even though that standing is not real or the activity of the green initiative is poor [12]. Some scholars have defined the term as the intentional misrepresentation of a firm's environmental efforts (or the lack thereof) [13,14]. Greenwashing is an interesting issue that has not been frequently discussed or examined empirically in the green marketing literature, and Indonesia, where green marketing and environmental practices are not as advanced as in the developed countries, it make for a good potential location for future research on greenwashing [15].Furthermore, Indonesia must learn from their neighboring country, Malaysia, which has a cultural proximity where the current business environment does not support the adoption of renewable energy technology, and thus, renewable energy technology is not commercially viable. Additionally, the population of Peninsular Malaysia associates the use of renewable energy with a high level of effort and therefore has a negative attitude towards the use of renewable energy technology [16].

The increased competitiveness within Asia, which has further increased following the ASEAN open skies in 2015, has resulted in Asia's network airlines responding with the growing use of low-cost-carriers or airlines-within-airlines. It is fundamental for these airlines to compete effectively so as to determine their likely success or failure. In Indonesia, the main players are the following three airlines; Garuda Indonesia, the state owned company; Lion Air, the biggest Indonesian LCC; and Air Asia Indonesia, the subsidiary of world's best class LCC, Air Asia. These three airlines represent Indonesia to implement the policy of using newly developed high tech aircraft and new energy, as well as friendly environment operation, in order to achieve the target of reducing emissions in the aviation sector. Garuda Indonesia is a full service airline but it is also run by an LCC by operating a subsidiary named Citilink. By expanding the business to green flight, the airline inevitably will reposition themselves as a green company, by distinguishing their competitive advantage on the greenness to avoid being perceived as a greenwashing. As an archipelago country, Indonesia faces serious limitations in connecting the whole country. Over the last decade, air transport has become a reliable solution as a mean to connect each area and province. Nowadays, it is the cheapest and fastest way to travel all around Indonesia with LCCs, and this captive market is very sensitive to price change.

The empirical studies have suggested marketing an entirely new high-tech products is expected to be a time-consuming and ambiguous journey $[17,18]$. Although there have been well accepted, a unique insight that the marketing strategy would emphasize on the specific segment called 'visionaries' and 'innovators' as the first adopters of the new high-tech products [19], a few clarifications were still found on how to identify the potential cohort inside the market that is non-existent.

The initial study [20] has provided respected understandings into the demographic profiles of green consumers, as follows: educated, wealthy, and under 55 years old, which is consistently true when examined in the U.S.A. [21,22], Canada [23], Germany [11,24], the Netherlands [25], and the U.K. [26]. However, if this segmentation is applicable within the Indonesian setting, further investigation will be needed as the marketing that is grounded on demographic consumer characteristics is ineffective [10]. Furthermore, the most current research in Indonesia on sustainability [27], is still approached by the classic Ajzen's Theory of Planned Behavior [28], where not much is revealed about what drives Indonesian consumers to purchase green high tech products. 


\section{Values and Purchasing Green High Tech Behavior}

Theorists [29-31] and marketers [32] believe that values cause the behavior of consumers. As such, currently, many scholars [33] have attempted to find particular types of values that are considered to influence pro-environmental beliefs and behaviors. An ecologically appropriate action could stem from three distinctive value bases, namely: for the welfare of other people (altruism), for oneself (egoism), and for all of the existing creatures (biospherism) [34-36]. The value-based approach for environmentalism has been additionally facilitated by Schwartz's universal-ide value theory [37].

The principles of the theory that was established by Schwartz has been verified on 200 respondents in 60 nations, including Indonesia, across an extensive range of behaviors [38]. Consequently, it has been leading in the values realm during the last two decades [39]. Values are thoughts or principles that are relating to required end situations, which surpass precise circumstances, lead choice or assessment of conduct and occasions, and are arranged by comparative significance [40]. The 10 motivational value styles are as follows: (a) achievement: individual accomplishment through the revelation of skill conferring to community standards; (b) benevolence: apprehension for the prosperity of others in daily contact; (c) conformity: restriction of actions, preference, and desire, possibly to trouble or hurt others and disrupt community beliefs or norms; (d) hedonism: liking and intense fulfilment for self; (e) power: realization of social standing, and mechanism or supremacy on people and resources; (f) security: protection, harmony, and solidity of people, of relationships, and self; (g) self-direction: self-governing belief and doing; (h) stimulation: pleasure, uniqueness, and contest in existence; (i) tradition: admiration, pledge, and admittance to the customs and ideas practiced or enforced on the person; ( $\mathrm{j}$ ) universalism: considerate, thankfulness, acceptance, and defense for the prosperity of all people and for the environment. The theory [37] is summarized in Figure 1.

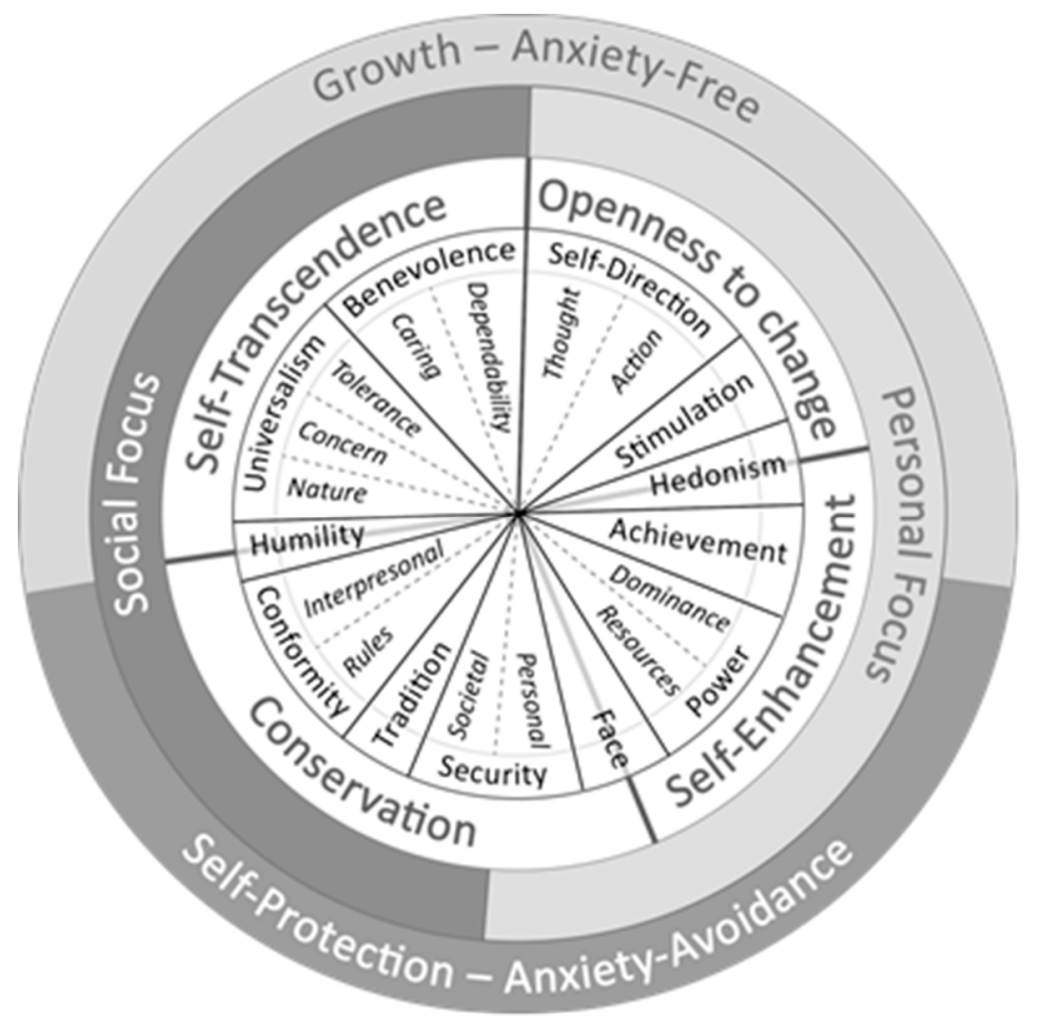

Figure 1. Circle of motivational range of 10 values in the value theory of Schwartz.

The study of value cannot be separated from Hofstede's classical work presenting the view of collectivism versus individualism [41]. Thus, some suggest that individualism and collectivism, serving 
fundamental beliefs about people's relationships and interactions with others, might have influences on individuals' environmental conducts [42,43]. Environmentally favorable attitudes and behaviors are driven more strongly by collective or/and self-transcending goals than by individual or/and self-enhancing concerns [33,44-46]. The self-transcendence values are universalism, benevolence, security, conformity, and tradition, while the self-enhancement values are self-direction, stimulation, hedonism, achievement, and power. Consequently, by using the conflicts between the value domains [37], researchers have explored why people involve themselves in pro-environmental activities so as to predict potential buyers of a green product.

Although Slatter and Mohr's [47], through the diffusion of innovation (DOI) theory, have provided a unique insight, namely that the marketing strategy should focus on the niche that consists of 'visionaries' and 'innovators' as the early adopters of the new high-tech products, not as much explanation can be found on how to identify and select the potential niches within the market that are non-existent in the country like Indonesia, where green marketing is still in an early infant stage. Technology enthusiasts or real innovators are those who are well-educated, make more substantial incomes, have a more pluralistic viewpoint, and have an enlarged participation in concerns outside of their groups. Visionaries adopt new high-tech products close to the early part of the product's lifecycle, but not as fast as the technology enthusiast. Visionaries look to technology enthusiast to tell them what the contemporary trends are and what the benefits of adopting them are [46]. LOHAS customers are described as people who place emphasis on developing a lifestyle of health and sustainability by endorsing undertakings that encourage the making of local, organic, and low-carbon nourishments [48].

The relationship among the constructs are shown on Figure 2.

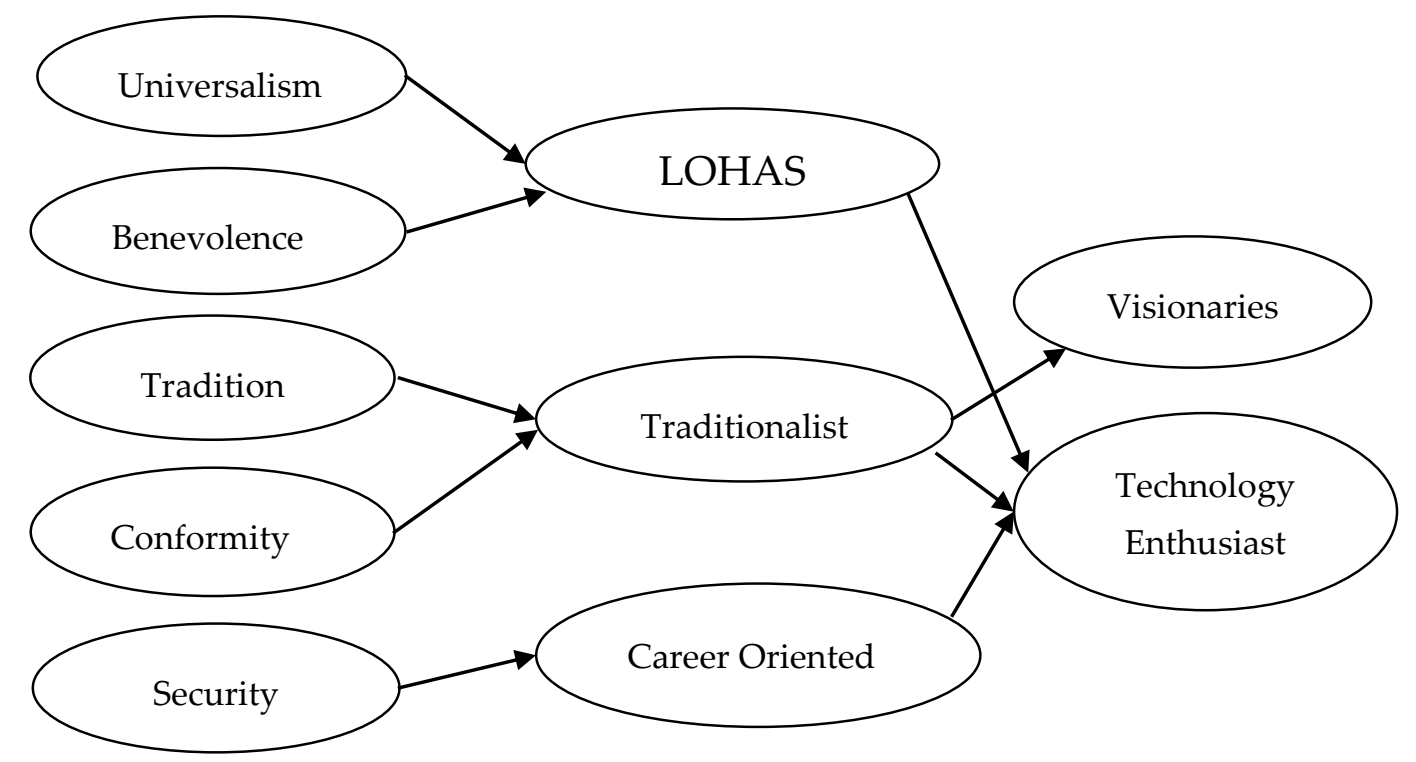

Figure 2. Model of profiling green high-tech consumers' values. LOHAS—Lifestyle of Health and Sustainability.

The diffusion of innovation (DOI) framework has been extensively employed to investigate early adopters' and potential adopters' perceptions of innovation characteristics in relation to many innovations and eco-innovations. However, most DOI research does not examine the role of an important factor, which some recent research has discussed, in the adoption of innovations, namely, values. Based on these findings on the role of values in the adoption of innovations, we believe that understanding the role of values in the adoption of green aviation is important as well. In a study of electric vehicle adoption [49], the consumer has assumed that the electric vehicle (EV) is an eco-innovation that has the potential to reduce the environmental problems of the transportation 
sector. Consequently, EV adoption behavior has been considered as a pro-environmental behavior and the factors that are related to pro-environmental behavior are often included in the analysis of predicting EV adoption. In this regard, the consumer EV adoption literature has mainly examined the roles of the pro-environmental attitudes, values, beliefs and norms, and their relationship with their intentions to purchase EVs. The perception of EVs' positive environmental impacts has also affected the intention to adopt EVs for potential EV adopters, which we believe will be applicable within air transport. Although some consumers might be unaware or skeptical about the possible environmental benefits of EVs, the adoption of EVs has been shown to be motivated by the consumer's pro-environmental attitudes, values, and beliefs.

Axsen's et al. [50] study has identified five clusters of potential adopters in the U.S.A., namely, engaged greens, aspiring greens, low-tech greens, traditionalists, and techies. The engaged greens are involved in pro-environmental and technology oriented lifestyle practices and are open to change. The aspiring greens are less involved with pro-environmental practices and have less interest in technology compared with the engaged greens, but also show openness to change.

Under this framework, the engaged greens and aspiring greens are more prone to adopt a green air travel model. The low-tech greens show the least openness to change and interest in technology, and compared with the last two clusters of greens, they are more likely to practice curtailment and non-consumption behavior (flying less and use of alternative modes of transportation instead of flying) rather adopting green air travel model. The two clusters of traditionalists and techies are low in engaging in pro-environmental practices and openness to change. However, the techies show an interest in technologies and are thus prone to adopting a green air travel model for the technological reasons and not for the environmental reasons. The techies resemble the traditionalist segment, which has a reactionary traditionalist attitude and approach towards the use of hi-tech products, and display a preference for the 'tried and tested' manual approaches.

The universalism values are inward harmony, the world at peace, a world of beauty, broad-minded, equality, protecting the environment, social justice, unity with nature, and wisdom. Individuals who cherish these values also feel convinced to protect the natural environment [40], as well as require the most significant stimulus on the choice so as to utilize fair trade choices [10].

Hypothesis 1. The market segment with the universalism value prefers to be Lifestyle of Health and Sustainability leading, compared with the technology enthusiast-minded, towards the Indonesian green air travel model.

Forgiving, helpful, honest, loyal, mature love, responsible, faithful friendship, meaning in life, and a spiritual life are the nine benevolence values. Surpassing selfish goals and fostering the well-being of those that are in-group are at the center of this value type. Observing the difference where benevolence prefers to reserve and improve the welfare of people with whom one is in regular personal interaction, and finding the values of being helpful and honest, are related to ethical intake [51].

Hypothesis 2. The market segment with the benevolence value prefers to be Lifestyle of Health and Sustainability leading, compared with the technology enthusiast-minded, towards the Indonesian green air travel model.

The security values are family security, national security, social order, clean, exchange of favors, sense of belonging, and health. The motivations of safety, harmony, and stability fortify these values. Security's objective is to rise above the ambiguity that comes with the self, relationships, and society [40]. Security values are alongside power values (self-enhancement value domains), which have been proven to be negatively associated with moderate trade intake [10].

Hypothesis 3. The market segment with the security value prefers to be career-oriented leading, compared with the technology enthusiast-minded, towards the Indonesian green air travel model. 
The principal aim of conformity is the limitation of actions, preferences, and impulses that are likely to trouble or harm others and interrupt social norms [40]. This condition implies that the person will wait and see and watch what most people will prefer.

Hypothesis 4. The market segment with the conformity value prefers to be traditionalist leading, compared with the visionaries-minded, towards the Indonesian green air travel model.

The motivational objectives of the traditional values are admiration, obligation, and the reception of the habits and ideas that one's culture or religion levies on the individual' [40]. In a collectivist culture, environmental concerns and green purchase behaviors are classified as a model of value-attitude-behaviors that have been worked out as the conceptual framework for envisaging a broad range of behaviors $[43,44]$.

Hypothesis 5. The market segment with the tradition value prefers to be traditionalist leading, compared with the visionaries-minded, towards the Indonesian green air travel model.

\section{Methodology of Research and Study Sample}

Following the demographic characteristics of the green consumers, namely, educated, prosperous, and below 55 years of age, the research questions were operationalized in a questionnaire that was adapted from Schwartz [40] for measuring the self-transcendence value. As such, the writer used a purposive sampling technique, as it was the most operative when one would need to examine a particular culture domain [52]. Purposive sampling was widely applied, including in comparing cultural practices [53]. The target population of this study was managers in the business sectors of Surabaya, the second largest city in Indonesia. The survey was focused on obtaining 200 respondents. Surabaya was chosen because the unique thing about Indonesian people was that the Javanese that were living in East Java, with the capital of Surabaya, were the largest and most dominant group. Although there were many other cultures within Indonesia, the influence of the attitudes that were rooted in traditional Javanese practices seemed particularly determinative of the work attitudes in business, where Javanese dominant political power was translated into prominence at most levels of the organizational practices and values [54]. The respondents were the frequent flyers using the service of Garuda Indonesia Airways-the full service carrier-during the period of January 2017 to January 2018. In Indonesia, Garuda Indonesia Airways was known as the most expensive airline, which was favored by the business people and high rank government officers, for it convenience and on-time departure. Interviewed at Garuda Executive Longue, these passengers were mostly managers and business owners that represented the criteria of educated, prosperous, and below 55 years of age. To investigate consumers' awareness of the LOHAS concept, the characteristics of their daily LOHAS behavior and attitudes concerning LOHAS consumptions were measured with questionnaires that were adapted from Li [55]. The highest score indicated those who were pursuing a Lifestyle of Health and Sustainability, the medium suggested traditionalists, and lowest indicated the career-oriented groups. The questionnaires that were used to segment the innovation adapters-technology enthusiast and visionaries-were developed from the work of Blackburn [46]. The percentage of technology enthusiasts and visionaries were observed to see the feasibility of marketing the product. Path analysis was used to determine the relationship between Lifestyle of Health and Sustainability (LOHAS) of the traditionalists and career-oriented compared to technology enthusiasts and visionaries. After validating, 178 data were ready for processing.

The seven-point Likert-type scales (1—strongly disagree; 7-strongly agree) were applied throughout the questionnaire. Universalism as an endogenous construct was measured with eight dimensions, namely: equality (X11), a world at peace (X12), unity with nature (X13), wisdom (X14), a world of beauty (X15), social justice (X16), broad-minded (X17), and protecting the environment (X18). Benevolence as an endogenous construct was measured with five dimensions, namely: loyal 
(X21), honest (X22), helpful (X23), responsible (X24), and forgiving (X25). Security as an endogenous construct was measured with seven dimensions, namely: family security (X31), national security (X32), social order (X33), cleanness (X34), reciprocation of favors (X35), sense of belonging (X36), and health (X37). Conformity, which was defined as the restraint of actions, inclinations, and impulses that were likely to upset or harm others and violate social expectations or norms, was measured with the following dimensions: self-discipline (X41), politeness (X42), honoring parents and elders (X43), and obedience (X44). Another endogenous construct, tradition, which was defined as respectfulness commitment, and acceptance of the customs and ideas that the traditional culture or religion provided, was measured with four dimensions, namely: devout (X51), respect for tradition (X52), humble (X53), and moderate (X54). The questionnaires for measuring values were adapted from Schwartz's Portrait Value Questionnaire (PVQ).

The exogenous variables of Lifestyle of Health and Sustainability (LOHAS), the traditionalists and career-oriented, were investigated through the agreement of their values on the following four dimensions, namely: holistic health, conservation, global social justice, and sustainable living [39]. The questionnaires to segment the innovation adapters, the technology enthusiasts and visionaries, were developed from the work of Slater and Mohr [19], Blackburn [46], and Pesek [56], where the visionaries were denoted as sensitive to group norms and values (y41), having had more of a local perspective (y42), likely to be opinion leaders (y43), adopting through technology enthusiasts' endorsements (y44), and cost-conscious (y45). The technology enthusiasts were reflected as those who were better educated (y51), with a cosmopolitan outlook (y52), high involvement outside of their communities (y53), depended less on group norms (y54), and had higher self-confidence (y55).

Since measurement with the Likert scale usually described agreement levels from strongly disagree to strongly agree, applying it directly to measure behavior would produce a sort of nuisance, which would lead the writer to reinterpret the scale as follwows: $1=$ not describe me at all, $2=$ not describe me, $3=$ somewhat not of me, $4=$ it may or may not describe me, $5=$ somewhat describes me, $6=$ it describes me, and $7=$ it describes me completely. The reinterpretation of the scaling model was applied by some scholars in the studying of various behaviors $[57,58]$.

\section{Results and Discussions}

\subsection{Results}

Respondents' frequency distributions that were based on their perception toward the indicators of the exogenous variables of LOHAS, technology enthusiasts and visionaries, is presented in Table 1. A simpler comprehension average score for each indicator is also presented. Although the respondents' frequency distribution scores were based on their perception towards the indicators as well as the averages, they did not provide information on the causal relationship of each variable. This information was beneficial to explain descriptively the value of each of the variables compared to the others.

The measurement model in Table 2 shows that the factor loading extracted all surpassed 0.50 and 0.70 , which indicated that the instrument had an acceptable convergent validity and construct reliability. The confirmatory factor analysis (CFA is) part of the larger family of methods, known as structural equation modeling (SEM), played an essential role in the measurement model validation in the path or structural analyses [59]. The CFA explicitly tested a priori hypotheses about the relations between the observed variables and latent variables or factors. The CFA was often the analytic tool of choice for developing and refining the measurement instruments, assessing construct validity, identifying method effects, and evaluating the factor invariance across time and groups. Under SEM, the confirmatory factor analysis (CFA) was usually inferred from the loading factors (0.50 above) [60]. The result that was presented indicated all of the loading factors, which was above 0.50 , and confirmed that each construct belonged to the respective variable. 
Table 1. Exogenous variables description.

\begin{tabular}{|c|c|c|}
\hline Variable Labels/Constructs & Questions & Average \\
\hline Holistic health (y11) & I am always concerned about my health and family health. & 5.66 \\
\hline Conservation (y12) & I always use environment-friendly products. & 5.20 \\
\hline Global social justice (y13) & I shape good moral and take care of other people. & 4.78 \\
\hline Sustainable living (y14) & $\begin{array}{l}\text { I am very keen on natural environment along with worry about } \\
\text { pollution of natural environment. }\end{array}$ & 5.51 \\
\hline Sensitive to group norms and values (y41) & $\begin{array}{l}\text { I may demand personalized solutions and quick-response, } \\
\text { highly-qualified sales and support when selecting new high tech } \\
\text { aircraft and a new renewable energy. }\end{array}$ & 5.66 \\
\hline Having more of local perspective (y42) & $\begin{array}{l}\text { I am attracted by high-risk projects like Indonesia Green Aviation } \\
\text { Initiative for sustainable development in air transportation. }\end{array}$ & 5.20 \\
\hline Likely to be opinion leaders (y43) & $\begin{array}{l}\text { I am motivated by the idea of being a change agent in my } \\
\text { reference group to use new high tech aircraft }\end{array}$ & 4.78 \\
\hline $\begin{array}{l}\text { Adopting through technology enthusiasts' } \\
\text { endorsements (y44) }\end{array}$ & $\begin{array}{l}\text { I am willing to try new technology in airport transportation if } \\
\text { some people begin to use this new service. }\end{array}$ & 5.51 \\
\hline Cost-conscious (y45) & $\begin{array}{l}\text { Since there is great gains from adopting innovation in new high } \\
\text { tech aircraft and a new renewable energy, I am willing to pay } \\
\text { more expensive for the service. }\end{array}$ & 5.29 \\
\hline Well educated (y51) & $\begin{array}{l}\text { Being highly educated, I look forward to adopt and use new high } \\
\text { tech aircraft and a new renewable energy to achieve } \\
\text { a revolutionary improvement. }\end{array}$ & 3.98 \\
\hline Cosmopolitan outlook (y52) & $\begin{array}{l}\text { I appreciate the introduction of new high tech aircraft and a new } \\
\text { renewable energy as the innovation. }\end{array}$ & 4.30 \\
\hline High involvement outside communities (y53) & $\begin{array}{l}\text { My interest in new air transport technology leads me out of } \\
\text { narrow circles of peers into broader circles of innovators }\end{array}$ & 5.44 \\
\hline Depending less on group norms (y54) & $\begin{array}{l}\text { I am willing to tolerate initial glitches and problems that may } \\
\text { accompany the introduction of high tech new aircraft and new } \\
\text { renewable energy in air transportation. }\end{array}$ & 5.98 \\
\hline Having greater self-confidence (y55) & $\begin{array}{l}\text { If there is a problem with the application of new technology in } \\
\text { aircraft and renewable energy, I am willing to develop makeshift } \\
\text { solutions to such problems. }\end{array}$ & 4.67 \\
\hline
\end{tabular}

An instrument could not be valid unless it was reliable. However, the reliability of an instrument did not depend on its validity. Although Cronbach's alpha was the most widely used to measure the reliability, this measurement might not have been the appropriate estimator, as it was very sample dependent [61]. The research instrument was reliable if the value of the construct reliability was $\left(\rho_{\eta}\right)>0.70[60,62,63]$.

Structural equation modeling often posed arguments on the model evaluation, as none of the models might have entirely covered all of the prerequisite settings [62,64], for example, a small value for the Chi-square statistic $\left(\chi^{2}\right)$ and the probability $(P)$ of a lesser amount of than 0.05 . However, these figures were once in a while accounted for and mostly disregarded by denoting to other alternative ways of evaluating the model fit [65]. The threshold values approaching 0.95 for the Tucker-Lewis index (TLI), 0.90 for the norm fit index (NFI), 0.90 for the incremental fit index (IFI), and 0.06 for the root mean square error of approximation (RMSEA), might have satisfactorily upkept the inference of a sensibly good fit between the proposed model and the data [63]. Other scholars recommended other goodness-of-fit statistics consisting of CMIN/DF (the minimum sample discrepancy function) supposed $\leq 2.0$ [66]; GFI (goodness-of-fit index) approximating 0.90, and AGFI (adjusted goodness-of-fit index) approaching 0.90 or higher [60].

By referring to the $\chi^{2}$ test $\left(\chi^{2}=1318.669\right)$ and probability $(p=0.01)$, this model could not capture the goodness-of-fit of the model, perhaps because the model was complicated and the because of the smallness of the sample size. However, when it was observed from other measurements, the model indicated an acceptable fitness of $\mathrm{CMIN} / \mathrm{DF}=1.137$ (expected smaller than 2), GFI $=0.778$ (marginal fit), AGFI $=0.767$ (marginal fit), CFI $=0.972$ (higher than 0.95), $\mathrm{TLI}=0.971$ (higher than 0.95), NFI $=0.881$ (close to 0.90 ), and IFI $=0.973$ (above 0.90 ). 
Table 2. Measurement information of convergent validity \& reliability.

\begin{tabular}{|c|c|c|c|}
\hline Construct & Loading Factors & Construct & Loading Factors \\
\hline $\begin{aligned} \text { Reliability }\left(\rho_{\eta}\right)=0.869 \\
\text { X11 } \leftarrow \text { Universalism } \\
\text { X12 } \leftarrow \text { Universalism } \\
\text { X13 } \leftarrow \text { Universalism } \\
\text { X14 } \leftarrow \text { Universalism } \\
\text { X15 } \leftarrow \text { Universalism } \\
\text { X16 } \leftarrow \text { Universalism } \\
\text { X17 } \leftarrow \text { Universalism } \\
\text { X18 } \leftarrow \text { Universalism }\end{aligned}$ & $\begin{array}{l}0.815 \\
0.824 \\
0.819 \\
0.826 \\
0.832 \\
0.821 \\
0.837 \\
0.820\end{array}$ & $\begin{aligned} \text { Reliability }\left(\rho_{\eta}\right)=0.779 \\
\text { X25 } \leftarrow \text { Benevolence } \\
\text { X24 } \leftarrow \text { Benevolence } \\
\text { X23 } \leftarrow \text { Benevolence } \\
\text { X22 } \leftarrow \text { Benevolence } \\
\text { X21 } \leftarrow \text { Benevolence }\end{aligned}$ & $\begin{array}{l}0.736 \\
0.844 \\
0.772 \\
0.854 \\
0.873\end{array}$ \\
\hline $\begin{aligned} \text { Reliability }\left(\rho_{\eta}\right)=0.893 \\
\text { X37 } \leftarrow \text { Tradition } \\
\text { X36 } \leftarrow \text { Tradition } \\
\text { X35 } \leftarrow \text { Tradition } \\
\text { X34 } \leftarrow \text { Tradition } \\
\text { X33 } \leftarrow \text { Tradition } \\
\text { X32 } \leftarrow \text { Tradition } \\
\text { X31 } \leftarrow \text { Tradition }\end{aligned}$ & $\begin{array}{l}0.813 \\
0.778 \\
0.775 \\
0.843 \\
0.864 \\
0.896 \\
0.836\end{array}$ & $\begin{array}{c}\text { Reliability }\left(\rho_{\eta}\right)=0.824 \\
\text { X44 } \leftarrow \text { Conformity } \\
\text { X43 } \leftarrow \text { Conformity } \\
\text { X42 } \leftarrow \text { Conformity } \\
\text { X41 } \leftarrow \text { Conformity }\end{array}$ & $\begin{array}{l}0.827 \\
0.787 \\
0.776 \\
0.804\end{array}$ \\
\hline $\begin{array}{c}\text { Reliability }\left(\rho_{\eta}\right)=0.903 \\
\text { X54 } \leftarrow \text { Security } \\
\text { X53 } \leftarrow \text { Security } \\
\text { X52 } \leftarrow \text { Security } \\
\text { X51 } \leftarrow \text { Security }\end{array}$ & $\begin{array}{l}0.864 \\
0.811 \\
0.733 \\
0.791\end{array}$ & $\begin{array}{c}\text { Reliability }\left(\rho_{\eta}\right)=0.780 \\
\text { y11 } \leftarrow \text { LOHAS } \\
\text { y12 } \leftarrow \text { LOHAS } \\
\text { y13 } \leftarrow \text { LOHAS } \\
\text { y14 } \leftarrow \text { LOHAS }\end{array}$ & $\begin{array}{l}0.803 \\
0.780 \\
0.778 \\
0.827\end{array}$ \\
\hline $\begin{aligned} \text { Reliability }\left(\rho_{\eta}\right)=0.768 \\
\text { y2 } 4 \leftarrow \text { Traditionalist } \\
\text { y23 } \leftarrow \text { Traditionalist } \\
\text { y22 } \leftarrow \text { Traditionalist } \\
\text { y21 } \leftarrow \text { Traditionalist }\end{aligned}$ & $\begin{array}{l}0.804 \\
0.788 \\
0.782 \\
0.812\end{array}$ & $\begin{array}{l}\text { Reliability }\left(\rho_{\eta}\right)=0.788 \\
\text { y34 } \leftarrow \text { Career Oriented } \\
\text { y33 } \leftarrow \text { Career Oriented } \\
\text { y32 } \leftarrow \text { Career Oriented } \\
\text { y31 } \leftarrow \text { Career Oriented }\end{array}$ & $\begin{array}{l}0.786 \\
0.799 \\
0.797 \\
0.821\end{array}$ \\
\hline $\begin{array}{c}\text { Reliability }\left(\rho_{\eta}\right)=0.742 \\
\text { y42 } \leftarrow \text { Visionaries } \\
\text { y43 } \leftarrow \text { Visionaries } \\
\text { y44 } \leftarrow \text { Visionaries } \\
\text { y45 } \leftarrow \text { Visionaries } \\
\text { y41 } \leftarrow \text { Visionaries }\end{array}$ & $\begin{array}{l}0.809 \\
0.822 \\
0.809 \\
0.808 \\
0.841\end{array}$ & $\begin{aligned} & \text { Reliability }\left(\rho_{\eta}\right)=0.972 \\
\text { y51 } & \leftarrow \text { Technology Enthusiast } \\
\text { y52 } & \leftarrow \text { Technology Enthusiast } \\
\text { y53 } & \leftarrow \text { Technology Enthusiast } \\
\text { y54 } & \leftarrow \text { Technology Enthusiast } \\
\text { y55 } & \leftarrow \text { Technology Enthusiast }\end{aligned}$ & $\begin{array}{l}0.773 \\
0.786 \\
0.804 \\
0.829 \\
0.847\end{array}$ \\
\hline
\end{tabular}

The summary of the full model of the research after the specification is observable in Figure 3. The result of the structural model analysis is observable in Table 3.

Table 3. Structural model result among constructs.

\begin{tabular}{ccccccccc}
\hline & & & Estimate & S.E. & C.R. & P & Conclusion \\
\hline LOHAS & $\leftarrow$ & Universalism & 0.265 & 0.071 & 3.711 & $* * *$ & Significant \\
LOHAS & $\leftarrow$ & Benevolence & 0.125 & 0.079 & 1.589 & 0.112 & Not \\
Traditionalist & $\leftarrow$ & Tradition & 0.371 & 0.100 & 3.705 & $* * *$ & Significant \\
Traditionalist & $\leftarrow$ & Conformity & 0.301 & 0.104 & 2.894 & 0.004 & Significant \\
Career Oriented & $\leftarrow$ & Security & 0.551 & 0.143 & 3.846 & $* * *$ & Significant \\
Technology enthusiast & $\leftarrow$ & LOHAS & 0.285 & 0.085 & 3.348 & $* * *$ & Significant \\
Technology enthusiast & $\leftarrow$ & Career oriented & 0.197 & 0.089 & 2.230 & 0.026 & Significant \\
Technology enthusiast & $\leftarrow$ & Traditionalist & 0.074 & 0.076 & 0.971 & 0.332 & Not \\
visionaries & $\leftarrow$ & Traditionalist & 0.321 & 0.073 & 4.384 & $* * *$ & significant \\
\hline
\end{tabular}

Notes: ${ }^{* * *}=p<0.00$.

The figures indicated that two paths, namely, LOHAS $\rightarrow$ benevolence, and technology enthusiast $\rightarrow$ traditionalist, were not significant. These paths were then excluded from the model for the purpose of the prediction of the prospective buyers of the green aviation initiatives for sustainable development in Indonesian air transportation. 


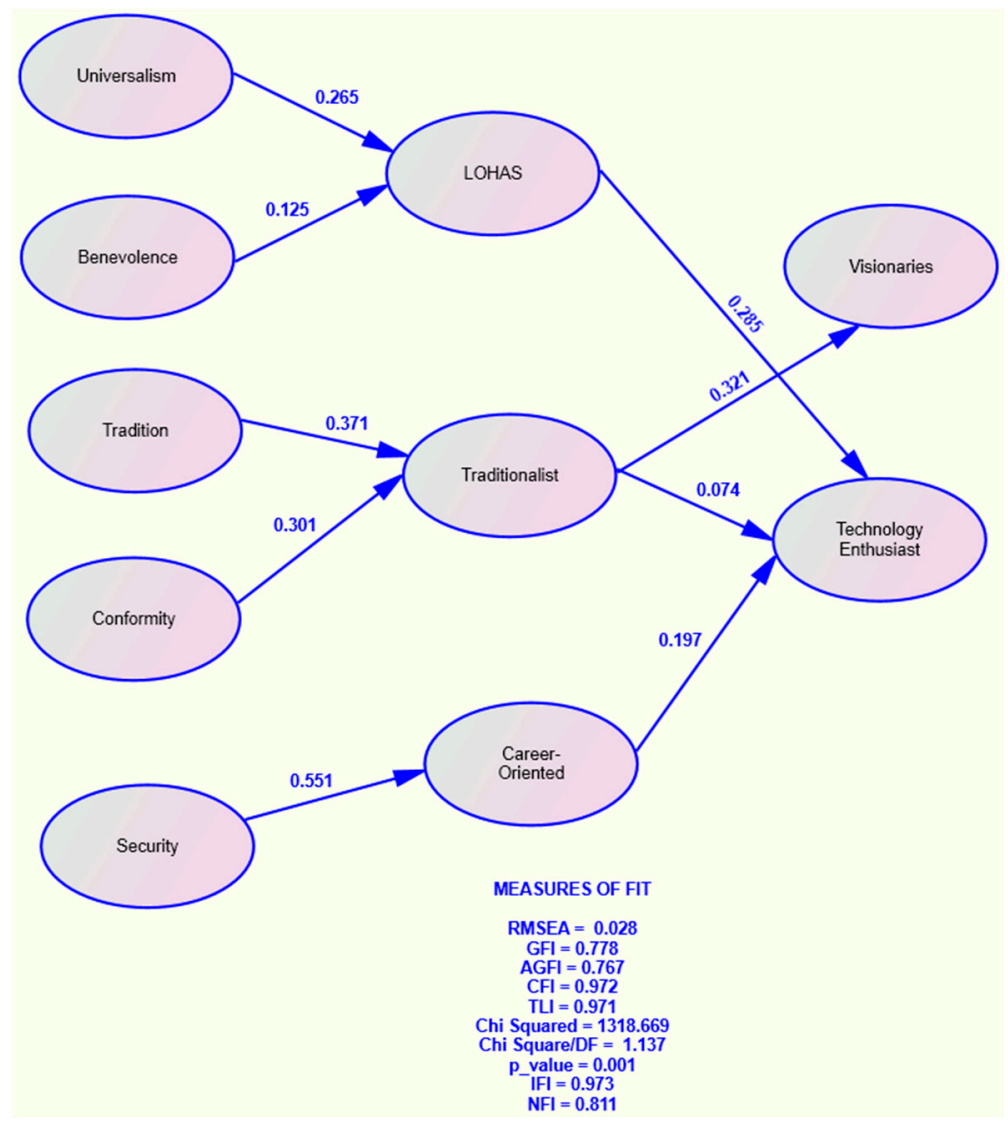

Figure 3. Summary of full model describing relationship among construct.

\subsection{Discussions}

This research was concentrated on the elaboration of the trends that enables the estimation of the prospective customers, with particular reference to personal values. The prediction was based on the significant path, by calculating the amount of the total effect, which was the total sum of the direct effect and the overall indirect effects. The indirect effect was the effect from the independent variable to the dependent variable that went through a mediator. If the direct effect was not significant, then the full mediation occurred [67]. The model of universalism $\rightarrow$ LOHAS $\rightarrow$ technology enthusiast, generated the direct effect of universalism to LOHAS $=0.265$, and the direct effect of LOHAS to technology enthusiast $=0.285$. This figure brought the total effect of $0.265 \times 0.285=0.0755$, which indicated that $7.55 \%$ of technology enthusiasts, when supporting the green aviation initiatives for sustainable development in air transportation, were predicted by universalism values with the condition that the consumers held the belief in Lifestyle of Health and Sustainability (LOHAS). Similarly, the model of security $\rightarrow$ career-oriented $\rightarrow$ technology enthusiast, generated the direct effect of security $\rightarrow$ career-oriented $=0.551$, and the direct effect of career-oriented to technology enthusiast $=0.197$, carrying the total effect of $0.551 \times 0.197=0.1085$, which indicated that $10.85 \%$ of technology enthusiasts, when supporting the Indonesian green air travel model, were predicted by the security values with the condition that the consumers accepted the habits and ideas that traditional culture or religion offered. Thus, these two models could be used to predict those who belonged to the technology enthusiasts. On the other hand, the model of conformity $\rightarrow$ traditionalist $\rightarrow$ visionaries produced the direct effect of conformity $\rightarrow$ traditionalist $=0.301$, and the direct effect of traditionalist $\rightarrow$ visionaries $=0.321$, resulting in the total effect of $0.301 \times 0.321=0.0966$, which indicated that $9.66 \%$ early adopters of the prospective supporters of the green aviation initiatives for sustainable development in air transportation were those who were restraint of actions, inclinations, and impulses that were likely to 
upset or harm others and violate social expectations or norms. By the same token, the model of tradition $\rightarrow$ traditionalist $\rightarrow$ visionaries produced the direct effect of tradition $\rightarrow$ traditionalist $=0.371$, and the direct effect of traditionalist $\rightarrow$ visionaries $=0.321$, resulting in the total effect of $0.371 \times 0.321=0.1190$, which indicated that $11.90 \%$ of the early adopters of the prospective supporters of the Indonesian green air travel model were those who were respecting commitment and accepting the customs and ideas that traditional culture or religion provided. Since this study argued that the Indonesian markets for renewable energy and green aviation transport were going to expand beyond the technology enthusiast or visionaries stages of diffusion, the paths recommended were security $\rightarrow$ career-oriented $\rightarrow$ technology enthusiast, and tradition $\rightarrow$ traditionalist $\rightarrow$ visionaries, as each path generated the highest total effect of $10.85 \%$ and $11.90 \%$, respectively.

Although the new consumer market niches, such as the so-called neo-greens or the LOHAS (lifestyle of health and sustainability), were rising in many countries, and there was an acknowledged market segment in the U.S.A., Western Europe, and Asian countries, including Japan, Singapore, and Taiwan, however, in the Indonesian setting, a greater proportion of the population did not show this trend. By referring to the LOHAS score, where the highest score was categorized into a Lifestyle of Health and Sustainability, medium for the traditionalists, the respondents of this research that display the lowest score were referred to as the career-oriented clusters, which meant that they had the least concern to holistic health, conservation, global social justice, personal growth, and sustainable living. They were active, calculating, and rational consumers who carefully allocated scarce resources to the purchase of goods and services in such a manner as to maximize the utility that was obtained. New practices in familiarizing green air traveling might not have delivered comfort for the consumers to obligate themselves to, until its cost and benefit analysis was confirmed satisfactorily [68].

The research proved the existence of the technology enthusiasts and visionaries-the groups that were interested in sustainable energy solutions-as the starting point for segmenting the market as well as the pioneering agents to disseminate the importance and urgency of shifting from using conventional products in aviation transport into the green high-tech products for national sustainability in preserving natural resources. This finding was in line with the insight that the marketing strategy should have emphasized on the niche that comprised of visionaries and technology enthusiasts as the early adopters of the new high-tech products $[69,70]$. Indonesian airlines were left behind in recognizing and addressing environmental concerns. Only recently had Indonesian airlines started to systematically promote environmental management at the corporate level. Although significant efforts were made in sustainability issues, such as fuel and water conservation, there was limited knowledge on the size and characteristics of the green marketplace in the Indonesian airline industry. With increased consumer awareness, an enhanced understanding of consumer profiles and their characteristics became vital to Indonesian airlines' environmental scenario. Since most of radically new high-tech products were presented in the niche market rather than the mass-market, this study explored how to identify and select the potential niches within the market in the setting of a developing country, Indonesia, so as to support the sustainability concept that was echoed in the Indonesian green air travel model, as not much enlightenment had yet originated on how to classify and select the prospective niches within the markets that were non-existent, primarily in a situation where the green high-tech products were still in an early infant phase. This study found out which values were salient to Indonesia, when wishing to adopt green high-tech products, which were then used as a basis for segmentation. This research found out that security and tradition were the values that were of paramount importance to people, so as to segment the market for high-tech green products, which supported the notions that values were more practical to profiling consumers and to segment markets, as in the developed countries [9-11]. They held positive attitudes towards the environment and showed the strongest environmental responsibility. It was recommended that airlines highlighted their environmental actions in order to prove their long-term commitment to environmental protection. This finding supported the lead-user theory [71] that users at the leading edge would have been best positioned to understand what would have been needed later by many. The lead users were 
defined as the members of a user population who (1) anticipated obtaining relatively high benefits from obtaining a solution to their needs, and so could innovate; and (2) were at the leading edge of important trends in a marketplace that were under study, and so were currently experiencing needs that would have later been experienced by many users in that marketplace [72]. Airlines might have considered a functional or rational strategy that delivered detailed information on environmentally beneficial product attributes or practices, such as the use of fuel-efficient engines or quieter aircraft, the provision of eco-friendly hand towels, and reusable cups for use in-flight, to effectively communicate a green image to the lead-user and to stimulate a more favorable perception among the potential customers. Furthermore, future environmental promotions and messages from the airlines might have needed to inspire a sense of environmental responsibility among the travelers in this cluster, in the hope that they would further participate with airlines' environmental measures. Constructing a meaningful advancement towards sustainability involved not only radical solutions on the development of new products and product substitutions among the targeted consumers, but also finding the niches which were willing to take a risk by trying an unproven product. This research suggested one solution, namely, using the value theory as a vehicle for marketing strategies specifically for the high-end tech product, to identify those people.

\section{Conclusions}

This study provides a way to identify and select the potential niches within the market in the setting of a developing country, Indonesia, which is collectivist. This way, Schwartz's self-transcendence values (security and tradition) represent a collective interests and serve as guiding principles when making a purchase decision for green high-tech products, like green aviation, confirming that the extent of consumers' environmental efforts will likely depend on their value orientations.

Because the path to green purchase behavior can vary as a function of personal values, the appeals of persuasive communication should also vary according to the values of the target [73-76]. Discussions that are aimed at promoting people's environmental attitudes and buying habits may try to match the focus of the expected benefits to the predominant values of the security, whose motivational goal is safety, harmony, and stability of society, of relationships, of self, and of tradition, whose motivational purpose emphasizes respect, commitment, and acceptance of the customs and ideas of one's culture or religion. This way, the policymaker does not consider all of Indonesian people as the target market of the green high-tech products of green aviation, because the segmenting philosophy is to 'select your market creatively!'.

This research had some limitations that had to be considered. Firstly, this study used cross-section data, which were not collected at several points in time, to support the findings. Second, only the relations between the absolute numbers of constructs were analyzed. Consequently, future research should scrutinize the other variables that could still possibly affect the investigated relationships. Finally, the attained results did not imply conclusive inference about the explored relationships and might have restricted generalizability because of the industries and geographical characteristics of the investigated sample. Future studies should be expanded to more extensive geographic territories, so that the findings will be generalizable for the developing country of Indonesia.

Author Contributions: The authors have read and approved the final manuscript.

Conflicts of Interest: The author declares no conflict of interest.

\section{References}

1. Li, Y.; Cui, Q. Carbon neutral growth from 2020 strategy and airline environmental inefficiency: A Network Range Adjusted Environmental Data Envelopment Analysis. Appl. Energy 2017, 199, 13-24. [CrossRef]

2. Cui, L.; Huang, Y. Exploring the Schemes for Green Climate Fund Financing: International Lessons. World Dev. 2018, 101, 173-187. [CrossRef]

3. Sood, A.; Tellis, G.J. Technological evolution and radical innovation. J. Mark. 2005, 69, 152-168. [CrossRef] 
4. Suprapto, M. Niche Applications for Introducing Radically New High-Tech Products to the Market: An Explorative Study. Ph.D. Thesis, Delft University of Technology, Delft, The Netherlands, 2010.

5. Gordon, R.; Carrigan, M.; Hastings, G. A framework for sustainable marketing. Mark. Theory 2011, 11, 143-163. [CrossRef]

6. Joshi, Y.; Rahman, Z. Factors affecting green purchase behaviour and future research directions. Int. Strateg. Manag. Rev. 2015, 3, 128-143. [CrossRef]

7. Do Paco, A.; Raposo, M. "Green" segmentation: An application to the Portuguese consumer market. Mark. Intell. Plan. 2009, 27, 364-379. [CrossRef]

8. Thompson, D.W.; Anderson, R.C.; Hansen, E.N.; Kahle, L.R. Green segmentation and environmental certification: Insights from forest products. Bus. Strategy Environ. 2010, 19, 319-334. [CrossRef]

9. De Pelsmacker, P.; Driesen, L.; Rayp, G. Do Consumers Care About Ethics? Willingness to Pay for Fair-Trade Coffee. J. Consum. Aff. 2005, 39, 363-385. [CrossRef]

10. Doran, C.J. The role of personal values in Fair Trade consumption. J. Bus. Ethics 2009, 84, 549-563. [CrossRef]

11. Müller, M.; Chassot, S.; Wüstenhagen, R.; Hübner, G. Profiling the green consumer: The role of personal values. In Sustainable Consumption-Towards Action and Impact Abstract Volume. In Proceedings of the International Scientific Conference, Hamburg, Germany, 6-8 November 2011.

12. Fernando, Y.; Shaharudin, M.S.; Wahid, N.A. Eco-innovation practices: A case study of green furniture manufacturers in Indonesia. Int. J. Serv. Oper. Manag. 2016, 23, 43-58. [CrossRef]

13. Alves, I.M. Green spin everywhere: How greenwashing reveals the limits of the CSR paradigm. J. Glob. Chang. Gov. 2009, 2, 1-17.

14. Furlow, N.E. Greenwashing in the new millennium. J. Appl. Bus. Econ. 2010, 10, 22.

15. Aji, H.M.; Sutikno, B. The extended consequence of greenwashing: Perceived consumer skepticism. Int. J. Bus. Inf. 2015, 10, 433-468.

16. Kardooni, R.; Yusoff, S.B.; Kari, F.B. Renewable energy technology acceptance in Peninsular Malaysia. Energy Policy 2016, 88, 1-10. [CrossRef]

17. Ortt, J.R.; van der Duin, P.A. The evolution of innovation management towards contextual innovation. Eur. J. Innov. Manag. 2008, 11, 522-538. [CrossRef]

18. Tellis, G.J.; Yin, E.; Bell, S. Global consumer innovativeness: Cross-country differences and demographic commonalities. J. Int. Mark. 2009, 17, 1-22. [CrossRef]

19. Slater, S.F.; Mohr, J.J. Successful development and commercialization of technological innovation: Insights based on strategy type. J. Prod. Innov. Manag. 2006, 23, 26-33. [CrossRef]

20. Ottman, J. The New Rules of Green Marketing: Strategies, Tools, and Inspiration for Sustainable Branding; Routledge: Abingdon-on-Thames, UK, 2017.

21. Wiser, R.H. Using contingent valuation to explore willingness to pay for renewable energy: A comparison of collective and voluntary payment vehicles. Ecol. Econ. 2007, 62, 419-432. [CrossRef]

22. Zarnikau, J. Consumer demand for 'green power' and energy efficiency. Energy Policy 2003, 31, 1661-1672. [CrossRef]

23. Rowland, I.; Faughnan, M.; Hoey, L.; Wahala, K.; Williamson, G.; Cassidy, A. Bioavailability of Phyto-oestrogens. Br. J. Nutr. 2003, 89, 838-869. [CrossRef] [PubMed]

24. Gössling, S.; Peeters, P.; Ceron, J.P.; Dubois, G.; Patterson, T.; Richardson, R.B. The eco-efficiency of tourism. Ecol. Econ. 2005, 54, 417-434. [CrossRef]

25. Arkesteijn, K.; Oerlemans, L. The early adoption of green power by Dutch households: An empirical exploration of factors influencing the early adoption of green electricity for domestic purposes. Energy Policy 2005, 33, 183-196. [CrossRef]

26. Diaz-Rainey, I.; Ashton, J.K. Profiling potential green electricity tariff adopters: Green consumerism as an environmental policy tool? Bus. Strategy Environ. 2011, 20, 456-470. [CrossRef]

27. Nadlifatin, R.; Lin, S.C.; Rachmaniati, Y.P.; Persada, S.F.; Razif, M. A pro-environmental reasoned action model for measuring citizens' intentions regarding ecolabel product usage. Sustainability 2016, 8, 1165. [CrossRef]

28. Ajzen, I. The theory of planned behavior. Organ. Behav. Hum. Decis. Process. 1991, 50, 179-211. [CrossRef]

29. Rohan, M.J. A rose by any name? The values construct. Personal. Soc. Psychol. Rev. 2000, 4, 255-277. [CrossRef]

30. Young, I.; Hendrick, S.; Parker, S.; Rajić, A.; McClure, J.T.; Sanchez, J.; McEwen, S.A. Knowledge and attitudes towards food safety among Canadian dairy producers. Prev. Vet. Med. 2010, 94, 65-76. [CrossRef] [PubMed] 
31. Pietrzak, M.B.; Balcerzak, A.P.; Gajdos, A.; Arendt, L. Entrepreneurial environment at regional level: The case of Polish path towards sustainable socio-economic development. Entrep. Sustain. Issues 2017, 5, 190-203. [CrossRef]

32. Lowe, A.C.T.; Corkindale, D.R. Differences in "cultural values" and their effects on responses to marketing stimuli: A cross-cultural study between Australians and Chinese from the People's Republic of China. Eur. J. Mark. 1998, 32, 843-867. [CrossRef]

33. Kim, Y. Understanding Green Purchase: The Influence of Collectivism, Personal Values, and Environmental Attitudes, and the Moderating Effect of Perceived Consumer Effectiveness. Seoul J. Bus. 2011, 17, 65-92.

34. Stern, P.C.; Dietz, T.; Kalof, L. Value orientations, gender, and environmental concern. Environ. Behav. 1993, 25, 322-348. [CrossRef]

35. Simanaviciene, Z.; Volochovic, A.; Cibinskiene, A. Features of energy saving potential in Lithuanian households. Equilib. Q. J. Econ. Econ. Policy 2016, 11, 145-157. [CrossRef]

36. Simanaviciene, Z.; Virgilijus, D.; Simanavicius, A. Psychological factors influence on energy efficiency in households. Oecon. Copernic. 2017, 8, 671-684. [CrossRef]

37. Schwartz, S.H. An overview of the Schwartz theory of basic values. Online Read. Psychol. Cult. 2012, 2, 11. [CrossRef]

38. Schwartz, S.H.; Bardi, A. Value hierarchies across cultures taking a similarities perspective. J. Cross-Cult. Psychol. 2001, 32, 268-290. [CrossRef]

39. Parks, L.; Guay, R.P. Can Personal Values Predict Performance? Evidence in an Academic Setting. Appl. Psychol. 2012, 61, 149-173. [CrossRef]

40. Schwartz, S.H.; Bilsky, W. Toward A Universal Psychological Structure of Human Values. J. Personal. Soc. Psychol. 1987, 53, 550-562. [CrossRef]

41. Hofstede, G. Asian management in the 21st century. Asia Pac. J. Manag. 2007, 24, 411-420. [CrossRef]

42. Kim, Y.; Choi, S.M. Antecedents of green purchase behavior: An examination of collectivism, environmental concern, and PCE. Adv. Consum. Res. 2005, 32, 592-599.

43. McCarty, J.A.; Shrum, L.J. The Influence of Individualism, Collectivism, and Locus of Control on Environmental Beliefs and Behavior. J. Public Policy Mark. 2001, 20, 93-104. [CrossRef]

44. Follows, S.B.; Jobber, D. Environmentally responsible purchase behavior: A test of a consumer model. Eur. J. Mark. 2000, 34, 723-746. [CrossRef]

45. Kahle, L.R.; Kennedy, P. Using the list of values (LOV) to understand consumers. J. Serv. Mark. 1988, 2, 49-56. [CrossRef]

46. Blackburn, H. Millennials and the adoption of new technologies in libraries through the diffusion of innovations process. Libr. High Technol. 2011, 29, 663-677. [CrossRef]

47. Slater, S.F.; Mohr, J.J.; Sengupta, S. Radical product innovation capability: Literature review, synthesis, and illustrative research propositions. J. Prod. Innov. Manag. 2014, 31, 552-566. [CrossRef]

48. Kim, M.J.; Lee, C.K.; Gon Kim, W.; Kim, J.M. Relationships between lifestyle of health and sustainability and healthy food choices for seniors. Int. J. Contemp. Hosp. Manag. 2013, 25, 558-576. [CrossRef]

49. Rezvani, Z.; Jansson, J.; Bodin, J. Advances in consumer electric vehicle adoption research: A review and research agenda. Transp. Res. D Trans. Environ. 2015, 1, 122-136. [CrossRef]

50. Axsen, J.; Goldberg, S.; Bailey, J. How might potential future plug-in electric vehicle buyers differ from current "Pioneer" owners? Transp. Res. D Trans. Environ. 2016, 1, 357-370. [CrossRef]

51. Shaw, D.; Grehan, E.; Shiu, E.; Hassan, L.; Thomson, J. An exploration of values in ethical consumer decision making. J. Consum. Behav. 2005, 4, 185-200. [CrossRef]

52. Tongco, M.D.C. Purposive Sampling as a Tool for Informant Selection. Ethnobot. Res. Appl. 2007, 5, 147-158. [CrossRef]

53. Neupane, R.P.; Sharma, K.R.; Thapa, G.B. Adoption of agroforestry in the hills of Nepal: A logistic regression analysis. Agric. Syst. 2002, 72, 177-196. [CrossRef]

54. Alatas, S.H. The Myth of the Lazy Native: A Study of the Image of the Malays, Filipinos and Javanese from the 16th to the 20th Century and Its Function in the Ideology of Colonial Capitalism; Routledge: Abingdon-on-Thames, UK, 2013.

55. Li, Q. Design of Eco Bags on the Basis of LOHAS and Consumption Behavior. Int. J. Environ. Sci. Dev. 2013, 4, 99-103. [CrossRef] 
56. Pesek, T.J.; Helton, L.R.; Nair, M. Healing across cultures: Learning from traditions. EcoHealth 2006, 3, 114-118. [CrossRef]

57. Gilbert, P.; McEwan, K.; Gibbons, L.; Chotai, S.; Duarte, J.; Matos, M. Fears of compassion and happiness in relation to alexithymia, mindfulness, and self-criticism. Psychol. Psychother. Theory Res. Pract. 2012, 85, 374-390. [CrossRef] [PubMed]

58. Teixeira, M.A.P.; Bardagi, M.P.; Lassance, M.C.P.; de Oliveira Magalhães, M.; Duarte, M.E. Career adapt-abilities scale-Brazilian form: Psychometric properties and relationships to personality. J. Vocat. Behav. 2012, 80, 680-685. [CrossRef]

59. Jackson, D.L.; Gillaspy, J.A., Jr.; Purc-Stephenson, R. Reporting practices in confirmatory factor analysis: An overview and some recommendations. Psychol. Methods 2009, 14, 6-23. [CrossRef] [PubMed]

60. Hair, J.F.; Black, W.C.; Babin, B.J.; Anderson, R.E.; Tatham, R.L. Multivariate Data Analysis; Pearson Prentice Hall: Upper Saddle River, NJ, USA, 2006.

61. Liu, Y.; Wu, A.D.; Zumbo, B.D. The impact of outliers on Cronbach's coefficient alpha estimate of reliability: Ordinal/rating scale item responses. Educ. Psychol. Meas. 2010, 70, 5-21. [CrossRef]

62. Schumacker, R.E.; Lomax, R.G. A Beginner's Guide to Structural Equation Modeling; Psychology Press: Hove, UK, 2004.

63. Hu, L.T.; Bentler, P.M. Cutoff criteria for fit indexes in covariance structure analysis: Conventional criteria versus new alternatives. Struct. Equ. Model. Multidiscip. J. 1999, 6, 1-55. [CrossRef]

64. Pilelienè, L.; Grigaliūnaitè, V. Colour temperature in advertising and its impact on consumer purchase intentions. Oecon. Copernic. 2017, 8, 657-669. [CrossRef]

65. Robins, R.W.; Fraley, R.C.; Krueger, R.F. (Eds.) Handbook of Research Methods in Personality Psychology; Guilford Press: New York, NY, USA, 2009.

66. Arbuckle, J.L. IBM SPSS Amos 19 User's Guide; Amos Development Corporation: Crawfordville, FL, USA, 2010.

67. Awang, Z. SEM Made Simple: A Gentle Approach to Learning Structural Equation Modeling; MPWS Rich Publication: Bangi, Malaysia, 1 August 2015.

68. Kot, S. Cost structure in relation to the size of road transport enterprises. Promet Traffic Traffico 2015, 27, 387-394. [CrossRef]

69. Oláh, J.; Bai, A.; Karmazin, G.; Balogh, P.; Popp, J. The role played by trust and its effect on the competiveness of logistics service Providers in Hungary. Sustainability 2017, 9, 2303. [CrossRef]

70. Cygler, J.; Sroka, W. Coopetition disadvantages: The case of the high tech companies. Eng. Econ. 2017, 28, 494-504. [CrossRef]

71. Schreier, M.; Prügl, R. Extending lead-user theory: Antecedents and consequences of consumers' lead userness. J. Prod. Innov. Manag. 2008, 25, 331-346. [CrossRef]

72. Franke, N.; Von Hippel, E.; Schreier, M. Finding commercially attractive user innovations: A test of lead-user theory. J. Prod. Innov. Manag. 2006, 23, 301-315. [CrossRef]

73. Jotanović, S.R.; Ratković, M.; Zakić, N. Pro-environmental activities of consumers. Pol. J. Manag. Stud. 2017, 16, 55-66. [CrossRef]

74. Thamrin, H.M. From goal orientation to manager performance: A case on managers of shipping company in Indonesia. Pol. J. Manag. Stud. 2016, 13, 175-182. [CrossRef]

75. Kowalska, K. Non-Market Factors of Competitiveness of Transport, Freight Forwarding and Logistics Companies. Forum Sci. Oecon. 2014, 2, 5-17.

76. Androniceanu, A.; Popescu, C.R. An inclusive model for an effective development of the renewable energies public sector. Adm. Manag. Public 2017, 28, 81-96.

(C) 2018 by the authors. Licensee MDPI, Basel, Switzerland. This article is an open access article distributed under the terms and conditions of the Creative Commons Attribution (CC BY) license (http:/ / creativecommons.org/licenses/by/4.0/). 